\title{
ANDANZAS DE UNA LÁPIDA CONMEMORATIVA COLOCADA EN EL ANFITEATRO DE ITÁLICA EN EL AÑO 1862
}

\author{
WANDERINGS OF A COMMEMORATIVE PLAQUE PLACED \\ IN THE AMPHITHEATER OF ITALICA IN 1862
}

\author{
JOSÉ MANUEL RODRÍGUEZ HIDALGO
}

\begin{abstract}
Resumen: El 23 de septiembre de 1862 Su Majestad la Reina Isabel II acudió a las Ruinas de Itálica. Lo hizo para ver las excavaciones que se efectuaban en el Anfiteatro. Para recordar y conmemorar el acto, las distintas instituciones organizadoras acordaron colocar una lápida de mármol. Tras el triunfo de "La Revolución Gloriosa”, el día 13 de octubre de 1868, el Ayuntamiento Provisional Revolucionario de Sevilla ordenó a la Comisión de Monumentos retirarla. En este artículo se describen las varias vicisitudes que acompañaron a esta lápida hasta su recuperación y colocación actual. También se tratan las vivencias de otras modernas placas conmemorativas que existen en el actual Conjunto Arqueológico de Itálica.

Palabras clave:Excavaciones en el Anfiteatro, Reina Isabel II, "Revolución Gloriosa", lápida conmemorativa, visitas Reales,
\end{abstract}

El 23 de septiembre de 1862, siguiendo una tradición centenaria, Su Majestad la Reina Isabel II acudió a las Ruinas de Itálica. Rodeada de un amplio séquito pisó la tierra donde según la tradición erudita, además de Trajano, nacieron Adriano, Teodosio, el poeta Silio, el mártir San Geroncio, etc., y sobre la que afamados poetas, como Fernando de Herrera, Rioja, Caro y otros muchos, evocaron con amargas lágrimas la destrucción de un pueblo cuyo esplendor expresaba un desgajado Anfiteatro, que ahora estaba siendo excavado bajo la dirección de Demetrio de los Ríos y el patrocinio de la Comisión de Monumentos Históricos y Artísticos, dependiente de la Junta Central de la Real Academia de la Historia, y también de la Diputación Provincial de Sevilla.

\begin{abstract}
On September $23^{\text {rd }} 1862$, Her Majesty Queen Isabella II visited the Ruins of Italica. The reason of her visit was to see the excavations being carried out in the amphitheatre. To commemorate the event, the various organizing institutions decided to place a marble plaque. After the victory of the "Glorious Revolution", on October $13^{\text {th }} 1868$, the Provisional Revolutionary Seville City Council ordered the removal of this plaque by the Monuments Commission. This article describes the various vicissitudes that surrounded this plaque until its recovery and current location. We also deal with the histories of other modern commemorative plaques that currently exist at the archaeological site of Italica.

Key words: Excavations in the amphitheatre, Queen Isabella II, Glorious Revolution, commemorative plaque, royal visits.
\end{abstract}

Esta visita Real supuso un gran respaldo a la Itálica del momento y a unas excavaciones que intentaban paliar las muchas destrucciones patrimoniales que se produjeron entre 1836 y 1856, cuando se cambió el trazado de la Carretera de Badajoz a su paso por Santiponce. Allí donde Ivo de la Cortina (1839/40) y José Amador de los Ríos (1840-46) simultanearon sus excavaciones con las obras de la carretera y los enfrentamientos con el Gobierno Civil, que ahora, además de promover y ejecutar las obras civiles, tenía que tutelar los bienes patrimoniales desamortizados, entre los que se encontraban las ruinas de Itálica, hasta entonces, 1835, propiedad del monasterio de San Isidoro del Campo, desde su fundación en 1301.

En aquellos momentos, pese a la descentralización y la mayor proximidad con los problemas que supuso la 


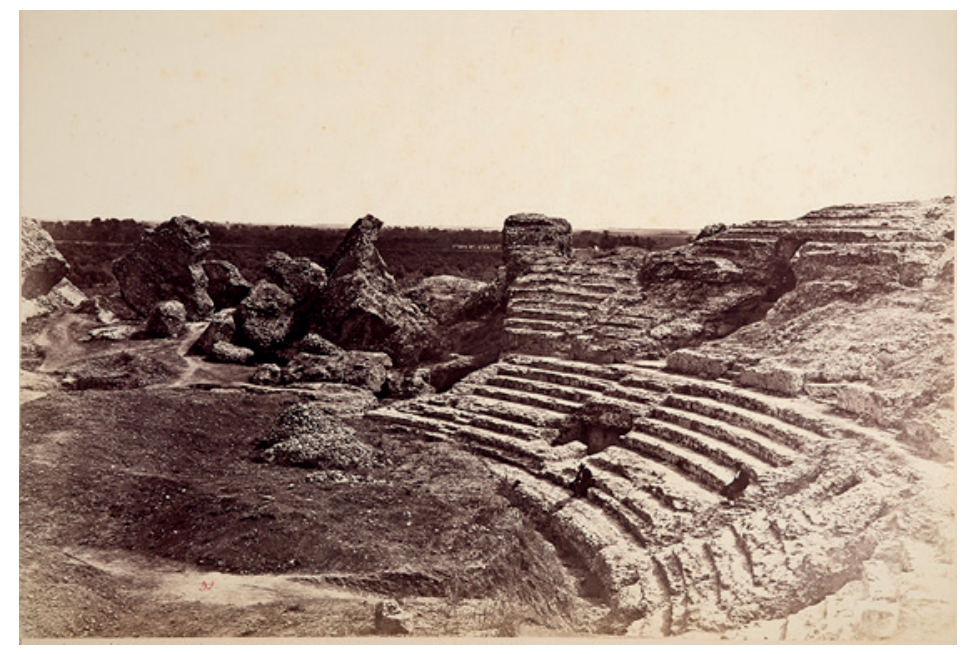

Figura 1. Fotografía de Charles Clifford, 1862. Estado del Anfiteatro tras las excavaciones realizada por Demetrio de los Río durante 1860-62, objeto de la visita de Isabel II. Colección J.M.R. Hidalgo. creación, el 13 de junio de 1844, de Comisiones Provinciales de Monumentos Históricos y Artísticos, se prodigaron las denuncias públicas en la prensa, y también en los despachos oficiales, pero aún así se siguieron produciendo destrozos por la explotación de "las canteras de Itálica" y la destrucción de los restos arquitectónicos que se exhumaban en esas excavaciones. Los enfrentamientos entre ambas posturas fueron especialmente virulentos en 1855; de una parte estaba el ingeniero jefe de la provincia de Sevilla, José Soler de Mena, y de otra, Demetrio de los Ríos, el arquitecto de la Provincia (Rodríguez Hidalgo, J. M., 2002, pp. 15-16)

Con el fin de resolver los litigios y paliar la situación, el 5 de diciembre de 1855, el gobernador civil, Mariano Castillo, convocó en la propia Itálica, al pie de las obras, a la Diputación Arqueológica, presidida y representada por Juan José Bueno y, su secretario, Antonio María de Ariza, a la Universidad Literaria y a la Comisión Provincial de Monumentos Históricos y Artísticos. Además de los citados, entre otros, estuvieron presentes Antonio del Canto Torralbo y Demetrio de los Ríos, que asistía en calidad de arquitecto de la Academia de Nobles Artes de San Fernando, de individuo de la Academia de Bellas Artes de Santa Isabel de Hungría, como arquitecto de la provincia de Sevilla y como Catedrático de la Escuela de Bellas Artes. Entre otras cuestiones, esa reunión de autoridades y expertos concluyó aceptando la necesidad y el compromiso de crear una plaza de guarda para las Ruinas de Itálica y de redactar y desarrollar un plan de excavaciones.

Tras unas primeras intervenciones arqueológicas realizadas durante 1856-7, la Comisión de Monumentos Históricos y Artísticos de Sevilla, en la sesión celebrada el 24 de enero de 1860, acordó nombrar a
Demetrio de los Ríos director facultativo de las excavaciones que habrán de hacerse en las ruinas de Itálica. Con sus excavaciones en el Anfiteatro, Demetrio de los Ríos dio comienzo a una nueva etapa y lo hizo cambiando el quehacer arqueológico, que repercutió en la fisonomía de las ruinas de Itálica, y especialmente en la de su Anfiteatro. Como arquitecto que era, con sus excavaciones en el Anfiteatro preconizó una arqueología más moderna frente a los criterios anteriores, más propios del modo de actuar del anticuariado de siglos precedentes. Él mismo en la página 33 de su libro $M e-$ moria Arqueológico-Descriptiva del Anfiteatro de Itálica (Madrid, 1862), se expresó en estos términos:

“...al hacerme cargo de la dirección expresada, juzgué de mi deber, para que fuesen realmente útiles las tareas que se proyectaban, el aconsejar a la Comisión que destine la suma concedida en el presupuesto de la provincia a la investigación del Anfiteatro, por parecerme preferible un estudio positivo a vagas exploraciones, sometidas al acaso, y por tanto de dudosos o estériles resultados".

Precisamente esta Memoria Arqueológico-Descriptiva, publicada por la Real Academia de la Historia, era el resultado de ese propósito aceptado por la Comisión y le sirvió a su autor para exponer los resultados y las deducciones a las que llegó tras las excavaciones efectuadas, especialmente entre los años 1860 y 1862 .

Ese mismo año de la publicación del libro, en concreto el 20 de mayo de 1862, Demetrio de los Ríos obtuvo el reconocimiento de sus trabajos, cuando la Diputación Arqueológica de Sevilla se dio cita en el Anfiteatro para presenciar los resultados de las excavaciones. Gracias a la crónica que redactó Aurelio Gali 


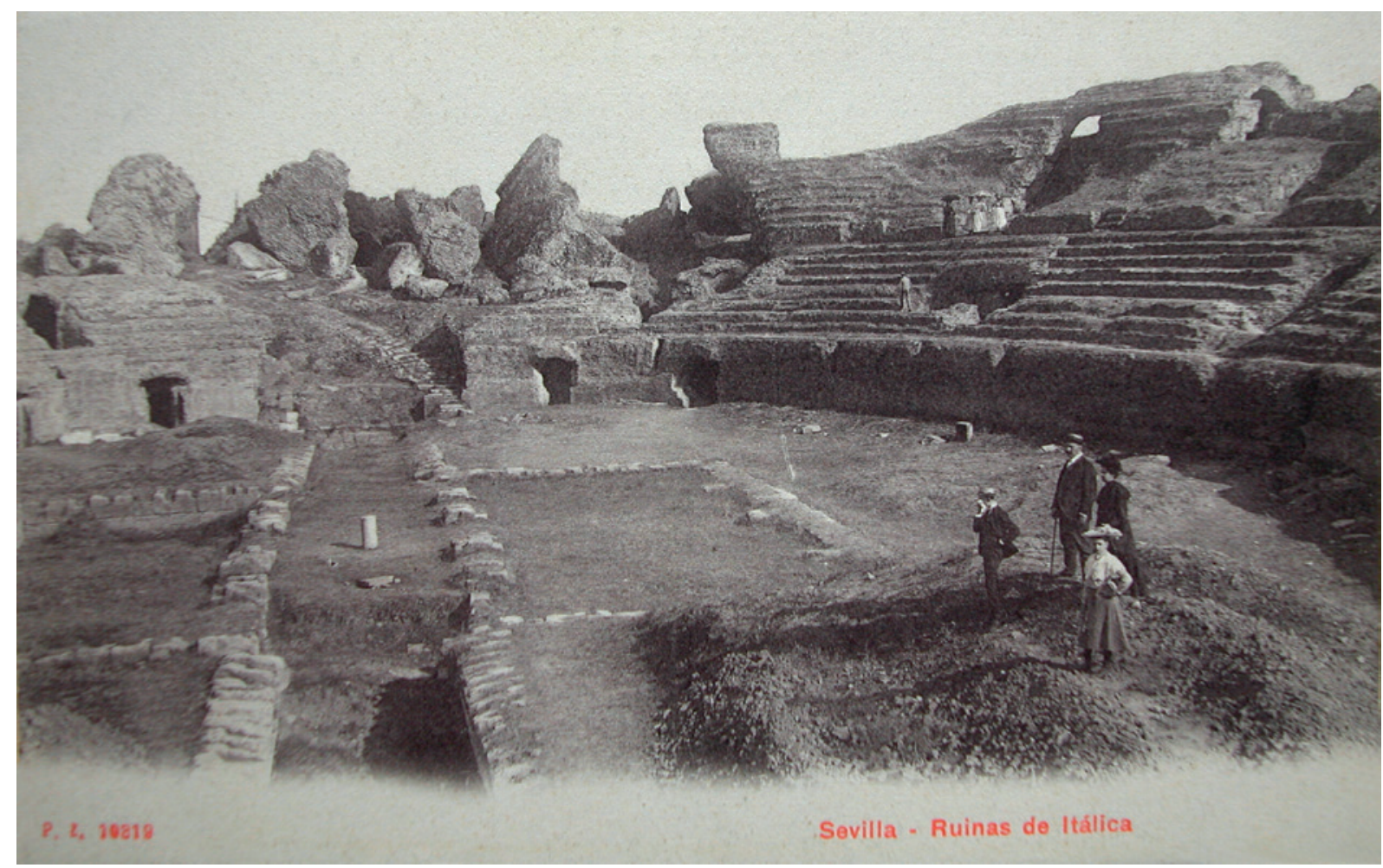

Figura 2. Tarjeta postal, La Unión Postal. Fotografía anónima realizada en la década de 1890. Colección J.M.R. Hidalgo.

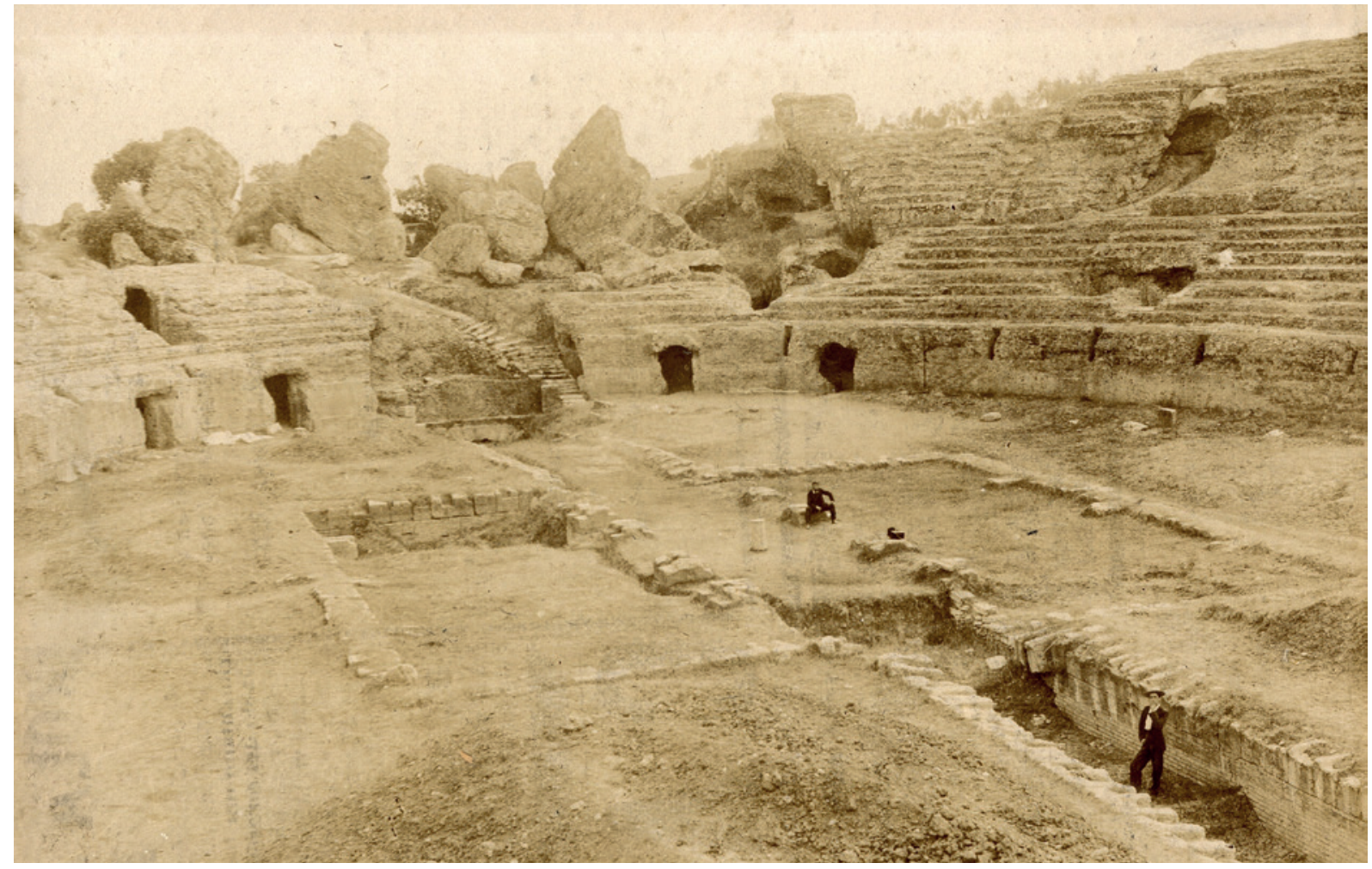

Figura 3. Fotografía anónima, hacia 1900. Colección J.M.R. Hidalgo.

ISSN: $1133-4525 \quad$ ISSN-e: $2255-3924$ 


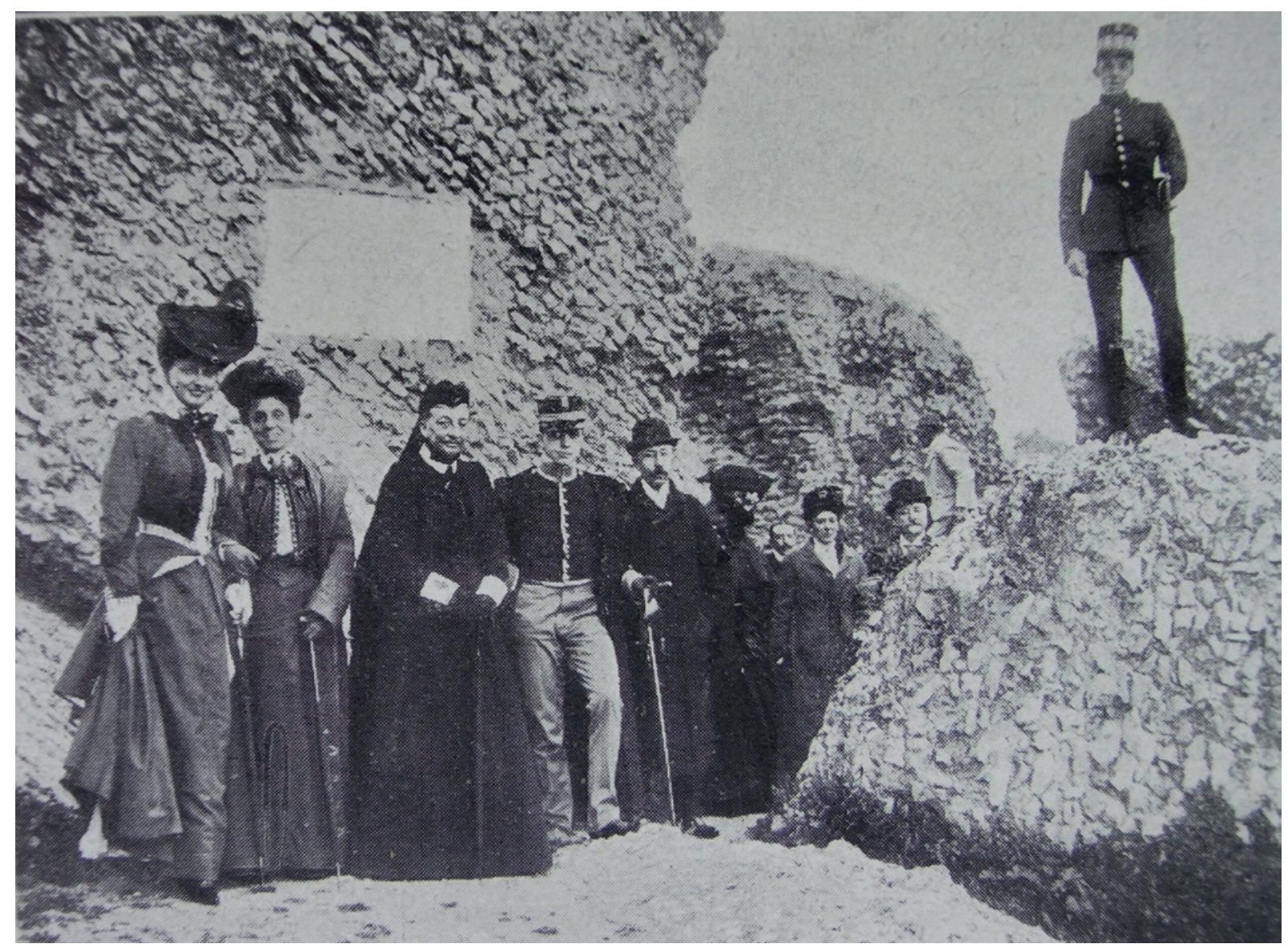

Figura 4. Nuevo Mundo, jueves 19 de abril de 1906. Don Alfonso XIII y los infantes Da María Teresa y D. Fernando, la condesa de París y su hija la princesa de Orleans, visitando las ruinas de Itálica el día 11 de abril de 1906. Colección J.M.R. Hidalgo.

Lassaletta (1892, pp. 77-78) podemos reconstruir los actos que acompañaron a esa visita:

"En una altura conveniente, para que desde ella pudiera divisarse el Anfiteatro, se había levantado una espaciosa tienda adornada con banderolas y alfombrada con flores rústicas y yerbas aromáticas que embalsamaban el ambiente. A las tres de la tarde llegó el Sr. Gobernador civil de la provincia, acompañado de 16 individuos de la Diputación, que ocupaban cuatro carruajes, siendo recibidos por una Comisión compuesta de los Sres. Hernández, Collantes y Secretario Ariza, a los cuales estaba encomendada la dirección de la ceremonia. A las tres y cuarto llegó una Comisión de la que formaban parte los Sres. Gago, pro. Lionnet, Cabriñana y Rapin, que habían pasado a la hacienda del Sr. D. Fernando Rodríguez de Rivas, para examinar las antigüedades descubiertas en la misma. Los concurrentes ocuparon una galería cubierta que domina las ruinas, e inmediatamente se abrió una sesión extraordinaria, presidida por el Sr.
Gobernador civil, que tenía a su derecha al Presidente de la Diputación Sr. Bueno y a la izquierda al Secretario Sr. Ariza: estos señores indicaron el objeto de aquel acto solemne, que no era sólo colocar el humilde monumento que se ha colocado en el Anfiteatro, sino también el ocuparse de la manera de continuar las excavaciones en lo sucesivo con el mejor éxito. Por el Sr. Marqués de Cabriñana, y a excitación del Sr. Presidente, se leyó la célebre oda de Rioja con una ligera biografía del ilustre poeta; por el Sr. Lamarque, la oda de Rodrigo Caro; por el Sr. Bueno, la oda de D. F. Núñez; y por el Sr. Collantes, el soneto de Pedro Quirós. El Sr. Cisneros leyó una Memoria alusiva al acto. El Sr. Marqués de Cabriñana un soneto a las ruinas de Itálica. El Sr. Lamarque una oda a las ruinas y dedicada a la Diputación; y por último, el Sr. Bueno un soneto y una octava.

Terminada la sesión, se trasladaron los concurrentes al centro del Anfiteatro, donde está colocado el trozo de columna que constituye el monumento, en el cual se han grabado los siguientes versos de Rioja: 


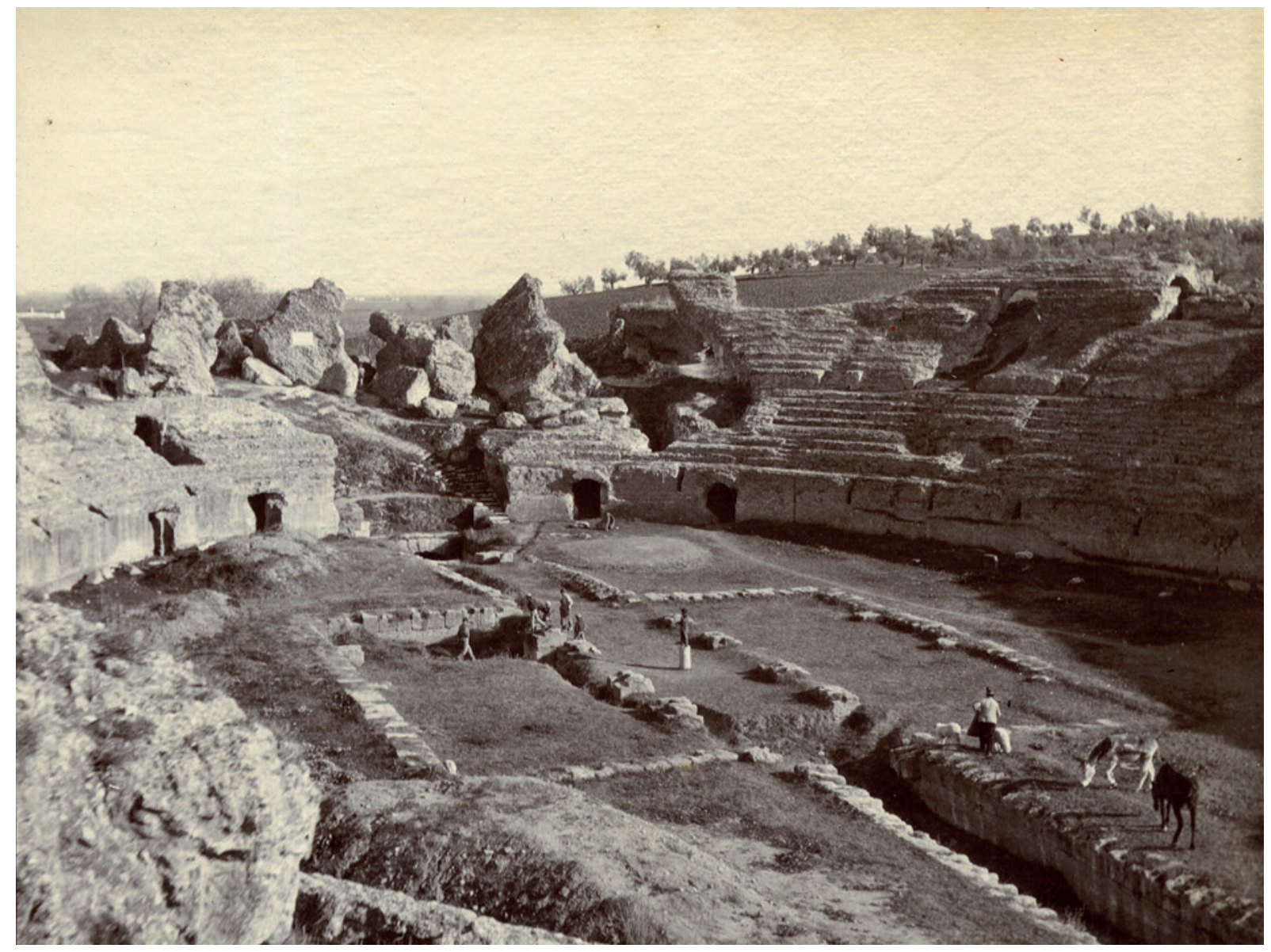

Figura 5. Fotografía de un viajero ingles fechada en 1910. Colección J.M.R. Hidalgo.

"Este despedazado anfiteatro

Impio honor de los dioses cuya afrenta

Publica el amarillo jaramago,

Ya reducido a trágico teatro, ¡Oh fábula del tiempo! Representa

Cuánta fue su grandeza y es su estrago.

La Diputación Arqueológica de Sevilla MDCCCLXII

Visitadas después las ruinas inmediatas, se trasladaron las personas que asistieron a la tienda, en cuyo centro estaba preparada una mesa cubierta de manjares, dulces y vinos. En este momento llegaron los Sres. Ríos y Colón; el primero de los cuales leyó una Memoria relativa al progreso de las excavaciones de algún tiempo a esta parte. Durante la comida brindaron los Sres. Gobernador Civil, Bueno y Almonte. Poco después visitaron los concurrentes el resto de las ruinas, regresando enseguida a la ciudad. En la sesión reinó gran entusiasmo y una extraordinaria animación. Concurrieron los Sres. Gobernador Civil de la provincia, Bueno, Cabriñana, Gaga, Lionnet, Rapin, Pila,
Cisneros (D. Antonio), Lamarque, Collantes, Hernández, Almonte, Fernández de los Ríos, Cañaveral, Ojeda, presbítero, Cortés, Ariza y en representación de la Comisión de Monumentos Históricos y Artísticos de la provincia, el Sr. Colón. A causa del mucho calor que se hizo sentir a la hora para que se citó a los socios, dejaron de concurrir muchos señores".

Pero el mayor reconocimiento a Itálica y a la labor de Demetrio de los Ríos se produjo con y tras la visita que, el 23 de septiembre de 1862, efectuó a las excavaciones S. M. Isabel II. El fastuoso acontecimiento no pasó desapercibido en la prensa local y nacional, tampoco en las múltiples crónicas regias que se redactaron tras esta visita inscrita en el viaje que SS. MM. y AA. RR. realizaron por las provincias de Andalucía y Murcia. Antes de la visita, ya el diario La Andalucía, de Sevilla, del domingo 21 de Septiembre, hacía una reseña sobre lo que sería la visita a Itálica y las personalidades que allí recibirían a SS. MM. El mismo día de la visita, 


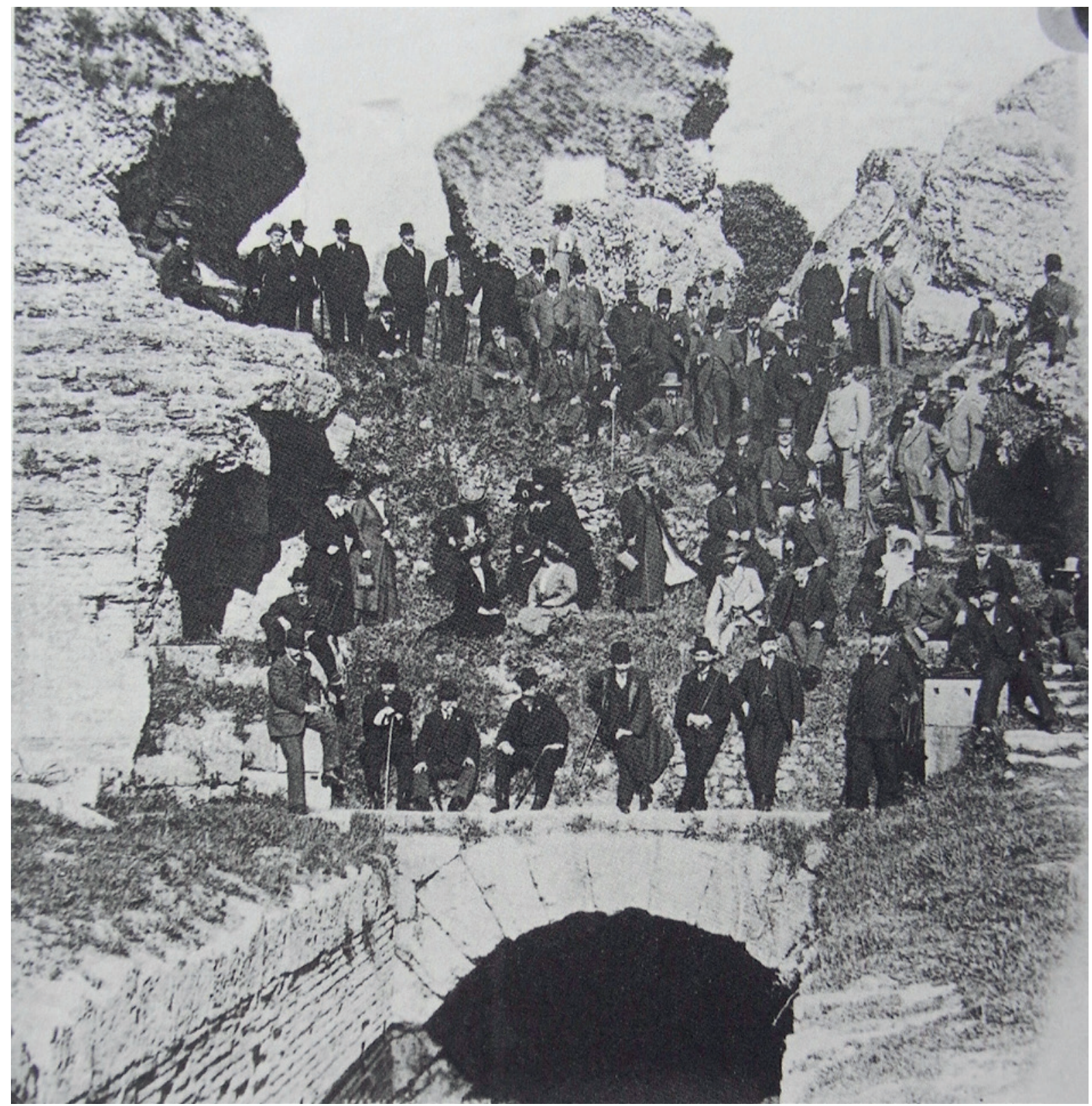

Figura 6. Portada del diario ABC de 18 de abril de 1910. Congreso de otorrinolaringólogos visitando las ruinas de Itálica.

Juan J. García de Vinuesa escribió en el diario El Porvenir de Sevilla lo siguiente:

“... SS.MM. han resuelto ir hoy a la Cartuja, magnífico establecimiento de los señores Pickman y Cía..., y después a las célebres ruinas de Itálica, (...). A la una de la tarde saldrá la familia regia del palacio de $\mathrm{S}$. Telmo (...) Acto continuo se dirigirán SS.MM. a las ruinas de Itálica por el arrecife provisional construido, pasando por las villas de Camas y Santiponce (...) Junto al extinguido monasterio de S. Isidoro del Campo se presentarán a SS.MM. los individuos de la comisión nombrada para arreglar este paseo de una manera cómoda y decorosa, componiéndola miembros de la Diputación Provincial, y Ayuntamiento, y de las Comisiones de Monumentos Históricos y Arqueológicos. Allí se invitará a las reales personas a que penetren en la iglesia (...) Seguidamente se 


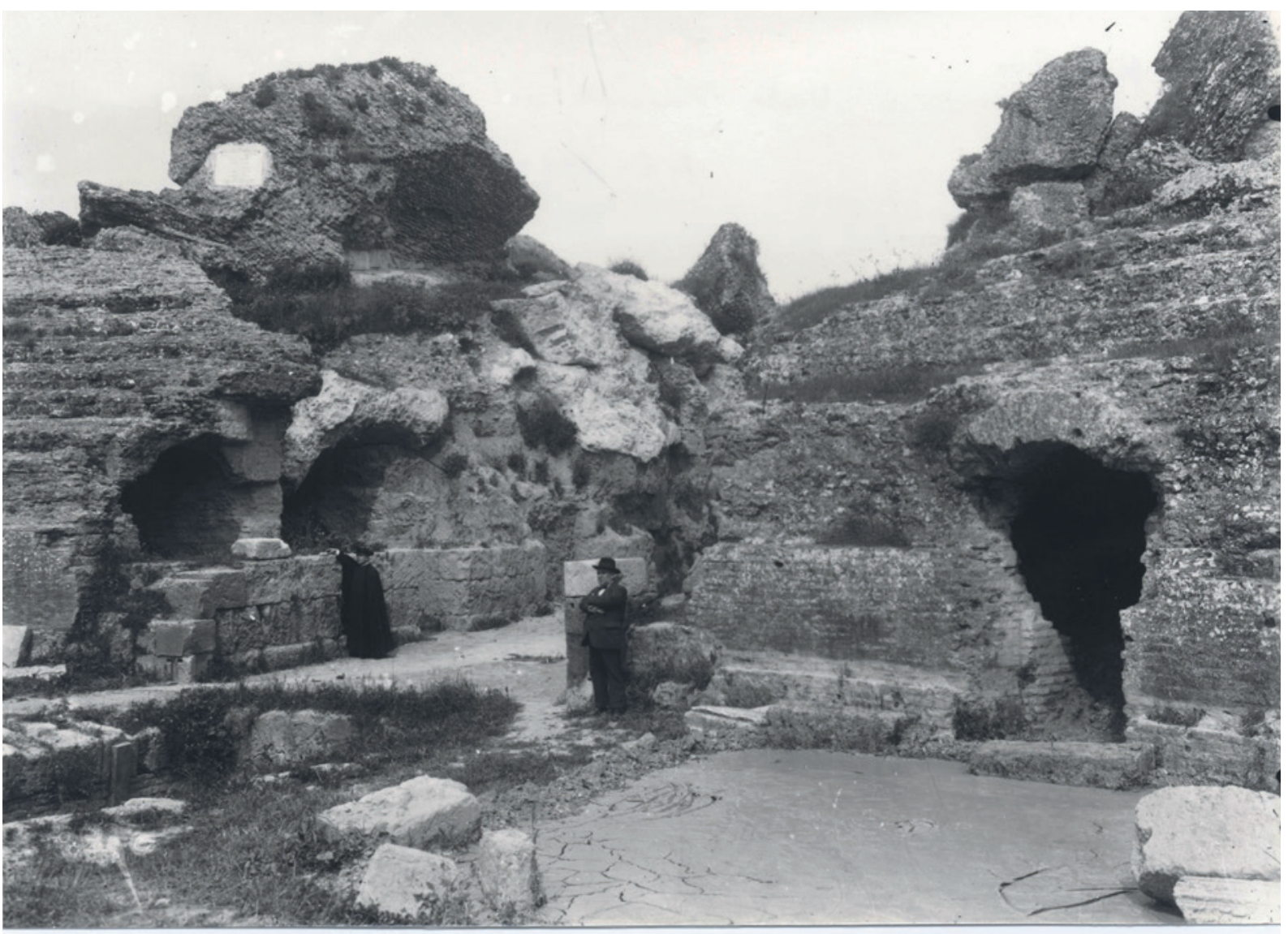

Figura 7. Fotografía de R. Salas tras el inicio de las excavaciones emprendidas por A. Parladé en la primera mitad de la década de 1920. Colección J.M.R. Hidalgo.

dirigirán SS.MM. a Itálica, apeándose al son de músicas militares y de otras de los pueblos circunvecinos en un extenso campamento, compuesto de numerosas tiendas, las cuales distribuidas por la planicie y las cumbres cercanas forman un pintoresco paisaje. En el centro se elevará la que se destina para descanso de las excelsas personas; ostentando en su remate el pabellón de España y apareciendo exornada con estandartes romanos de seda galoneadas de oro, en que están impresos con letras del mismo metal los nombres de los emperadores naturales de Itálica, de la arruinada colonia, su antiguo obispo y de los poetas que han celebrado sus glorias.

Luego que SS.MM. tomen asiento descorrerán los altos dignatarios, a quienes corresponda esta honra; a los acordes de la marcha Real, la Cortina de seda que cubrirá una lápida de mármol colocada en el circo con la inscripción siguiente:

\section{S.M. la Reina Doña Isabel segunda deseosa de ver la patria}

\author{
de los venerables Santos, \\ célebres poetas \\ e insignes Emperadores \\ estuvo en Itálica \\ el día 23 de Septiembre de 1862 \\ La Diputación Provincial \\ El Ayuntamiento de Sevilla \\ y la Comisión de Monumentos Históricos \\ y Arqueológica \\ cuidaron de perpetuar en este mármol \\ la memoria de tan fausto suceso
}

Después el Presidente de la Comisión de Monumentos llamará la atención de los reyes acerca de la importancia de las excavaciones, que se costean de los fondos provinciales, y don Demetrio de los Ríos; arquitecto director de las mismas, mostrará a SS.MM. el plano de la famosa y arruinada ciudad, por si gustan examinarlo, a fin de que puedan conocer su perímetro, la situación de sus principales monumentos y el circuito de sus murallas; presentándoles además una reseña de los trabajos ejecutados bajo su dirección. 
SS.MM. pasarán a ver detenidamente el despedazado anfiteatro, penetrando en los departamentos descubiertos y galerías subterráneas, para cuyo fin se han dispuesto terraplenes y escalinatas que faciliten el tránsito. Terminada la inspección de las ruinas, se obsequiará a las reales personas con un ligero refresco, si se dignaran a aceptarlo y después regresarán SS.MM. a Sevilla; cuidándose por la diputación arqueológica de que se tome una vista fotográfica del acto.

Afortunadamente para Itálica, la visita Real llevó aparejada la asignación de 10.000 reales para continuar los trabajos arqueológicos emprendidos. Con ellos Demetrio de los Ríos continuó con la excavación de la arena durante el año 1863 (fig.1). Unas excavaciones que se sucedieron con continuidad hasta el año 1868, más concretamente hasta que "La Revolución Gloriosa" disolvió la Academia Española de Arqueología del Príncipe Don Alfonso y con ella las diputaciones existentes en las provincias. Poco tiempo después de triunfar la Gloriosa, ésta tuvo su primera repercusión en Itálica. El día 13 de octubre de 1868, el Ayuntamiento Provisional Revolucionario de Sevilla dirigió a la Comisión de Monumentos la siguiente imposición:

Suprimidas las lápidas establecidas en varios edificios públicos, con el fin de consignar el viaje de la Corte a esta población en 1862, el Ayuntamiento se dirige a V.I. esperando que se servirá ordenar se retire la que se colocó en las ruinas de Itálica para conmemorar la visita que hizo a aquel sitio $\mathrm{D}^{\mathrm{a}}$ Isabel de Borbón.

Durante el Sexenio Revolucionario, a pesar de la crisis política que se atravesaba, por documentos del Archivo de la Comisión de Monumentos, sabemos que en 1870 se realizaron obras en el Anfiteatro, aunque no podemos especificar nada de las mismas porque la documentación existente es parca al respecto, limitándose tan sólo a anotar la continuación de los trabajos existentes. Seguramente se seguiría excavando la arena. Esto quedó confirmado con una misiva del Gobierno Provincial de fecha 28 de Diciembre de 1871, según la cual la Comisión de Monumentos invirtió 4.000 escudos en el Anfiteatro; tampoco se especificó nada al respecto, aunque presumiblemente se invirtieron una vez más en la excavación de la Arena.

La Restauración borbónica, al igual que la Revolución, también tuvo repercusiones en Itálica. Con la carta, que a continuación leeremos, remitida por el Alcalde de Sevilla, José de Solís y Jácome, el día 21 de diciembre de 1875, a la Comisión de Monumentos se inició una ajetreada situación en torno a la ya mencionada lápida de la visita de Isabel II, que, iniciada con la Orden dictada por el Ayuntamiento Provisional Revolucionario de Sevilla el día 13 de octubre de 1868, duró hasta el año 1991.

... ofreciéndose el Ayuntamiento Reunido en Cabildo otra nueva inscripción... Al propio tiempo estimó oportuno el Excmo. Ayuntamiento que se agregase a la inscripción lo siguiente: Borrada la inscripción conmemorativa que antecede, el Consejo Municipal de M.N.M.L.M.H. e I. ciudad de Sevilla, presidido por el Excmo. Sr. Don José Luis de Solís y Jácome, Marqués de Fablantes, acordó en Cabildo de 20 de noviembre de 1875 , volver a colocar en este sitio la piedra que advierta a la posterioridad tan glorioso acontecimiento.

Lo que tengo la satisfacción de participar a V.I. para su debido conocimiento y a fin de que sirva dar noticia del citado acuerdo a la Comisión que tan dignamente preside esperando que al mismo tiempo tendrá bondad de dar las órdenes oportunas al encargado de la custodia de las mencionadas ruinas de Itálica para que no le ponga impedimento a los dependientes de esta Alcaldía, que han de llevar a cumplido efecto lo dispuesto en el Municipio.

Como respuesta a lo trasladado por la Comisión de Monumentos el encargado de la custodia de las ruinas de Itálica, el guarda de las mismas, Manuel Fuentes, remitió, con fecha 16 de enero de 1876, la siguiente misiva de contestación:

En contestación a la respetada orden para aberiguar el paradero de la losa que en el, se refiere, echas las bestigaciones necesarias a dicho objeto le participo que se halla la referida losa en la casa del ayuntamiento en poder del alcalde de esta villa. Lo que tengo el honor de participar a V.I. para los fines oportunos a que haya lugar.

Con lo informado por el guarda Manuel Fuentes, la Comisión de Monumentos remitió al Sr. Alcalde Presidente del Excmo. Ayuntamiento de Sevilla el siguiente escrito:

En contestación a su atento oficio debo manifestarle, que esa Corporación de su digna Presidencia puede excusarse de esculpir otra lápida y exponerse a cometer en ella errores involuntarios, si emplea para su restitución en el Anfiteatro de Itálica, la misma que allá se colocó en la Visita Regia de 1862, a la que ese Excmo. Ayuntamiento puede agregar lo que tenga por conveniente.

$\mathrm{Al}$ efecto indico a V.E. que la lápida en cuestión se halla depositada en la Casa Capitular de la villa de Santiponce y que esta Corporación, se congratula de la reaparición en su lugar de semejante monumento conmemorativo, a cuyo acto contribuirá con su 


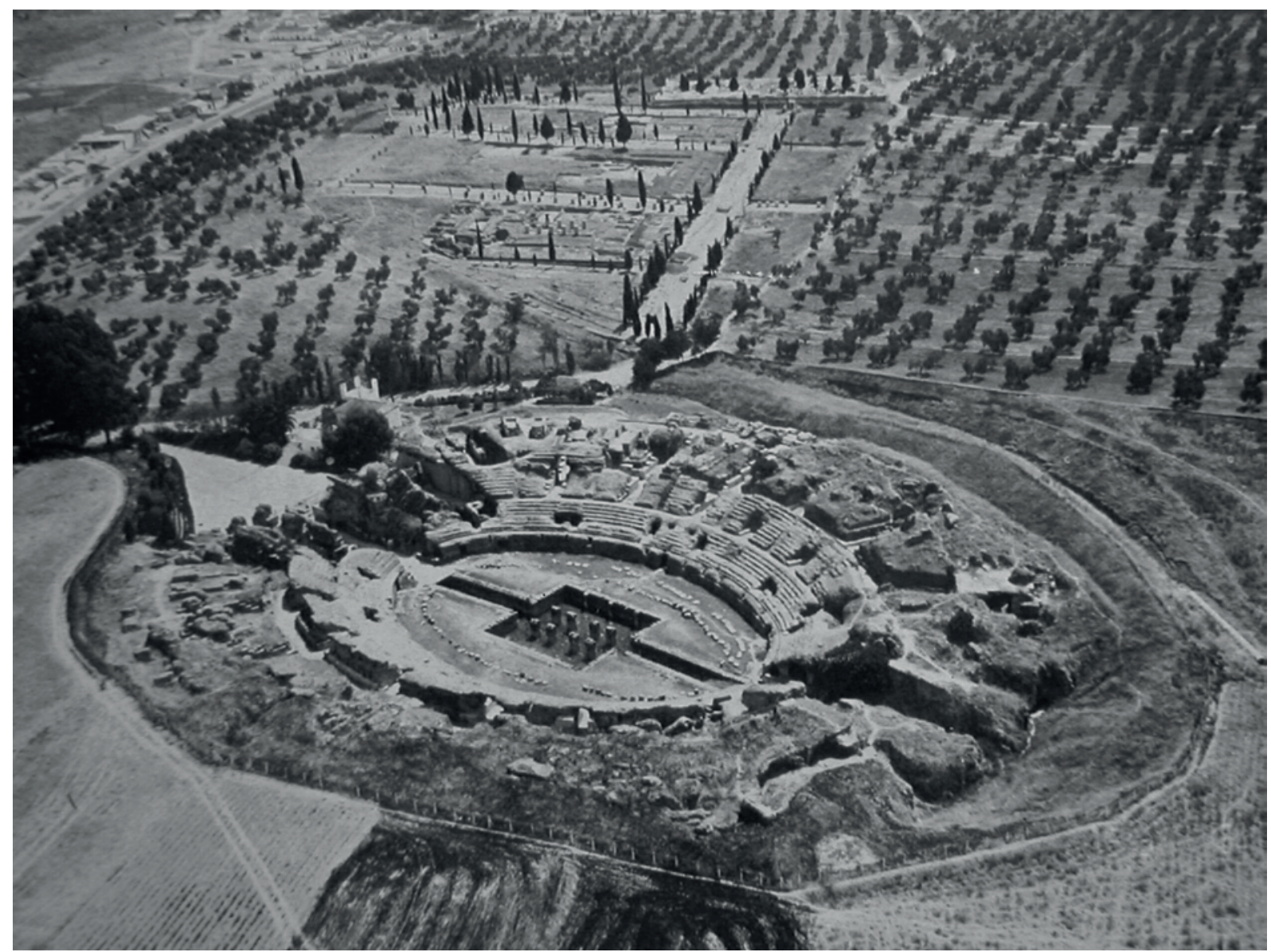

Figura 8. Fotografía aérea de finales de la década de 1960. En la parte central izquierda se observa la Casa-Museo donde, en 1912, tras su declaración como tal, se colocó la placa de mármol: ITÁLICA Monumento Nacional. Archivo del Conjunto Arqueológico de Itálica.

Figs. 9. Fachada de la Casa-Museo demolida en los primeros años de 1970, sustituida por la actual sede institucional del Conjunto, antes Museo. Archivo del Conjunto Arqueológico de Itálica.

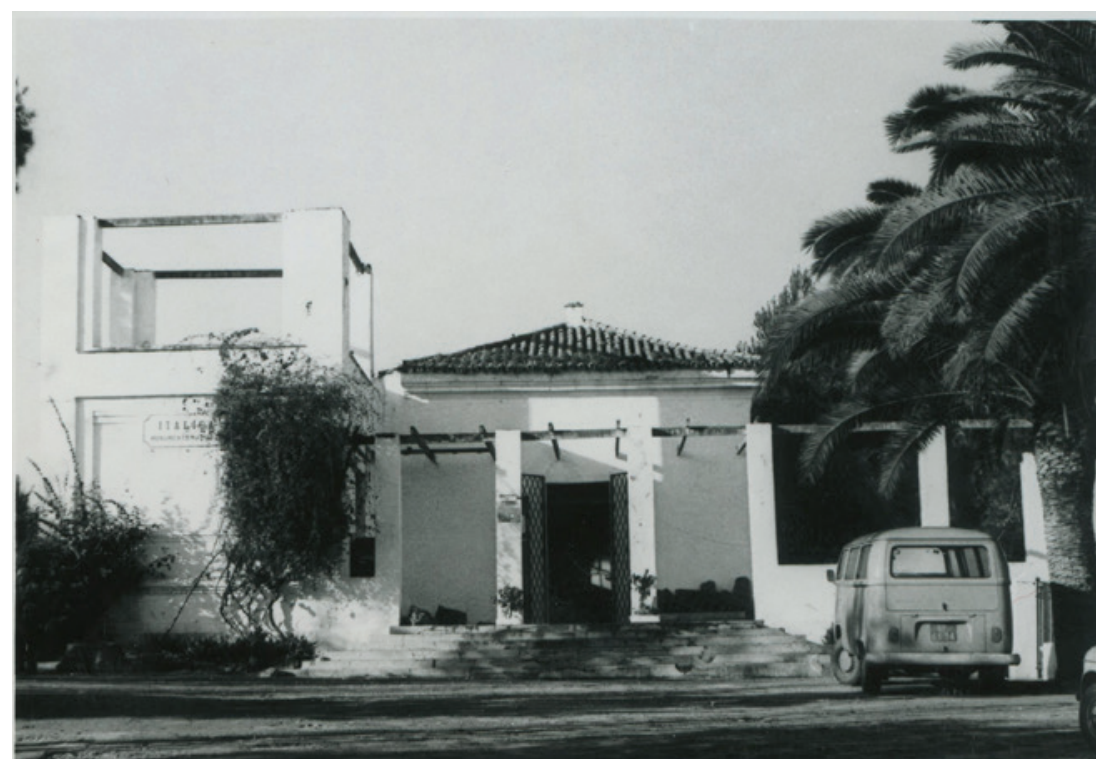

ISSN: 1133-4525 ISSN-e: 2255-3924 

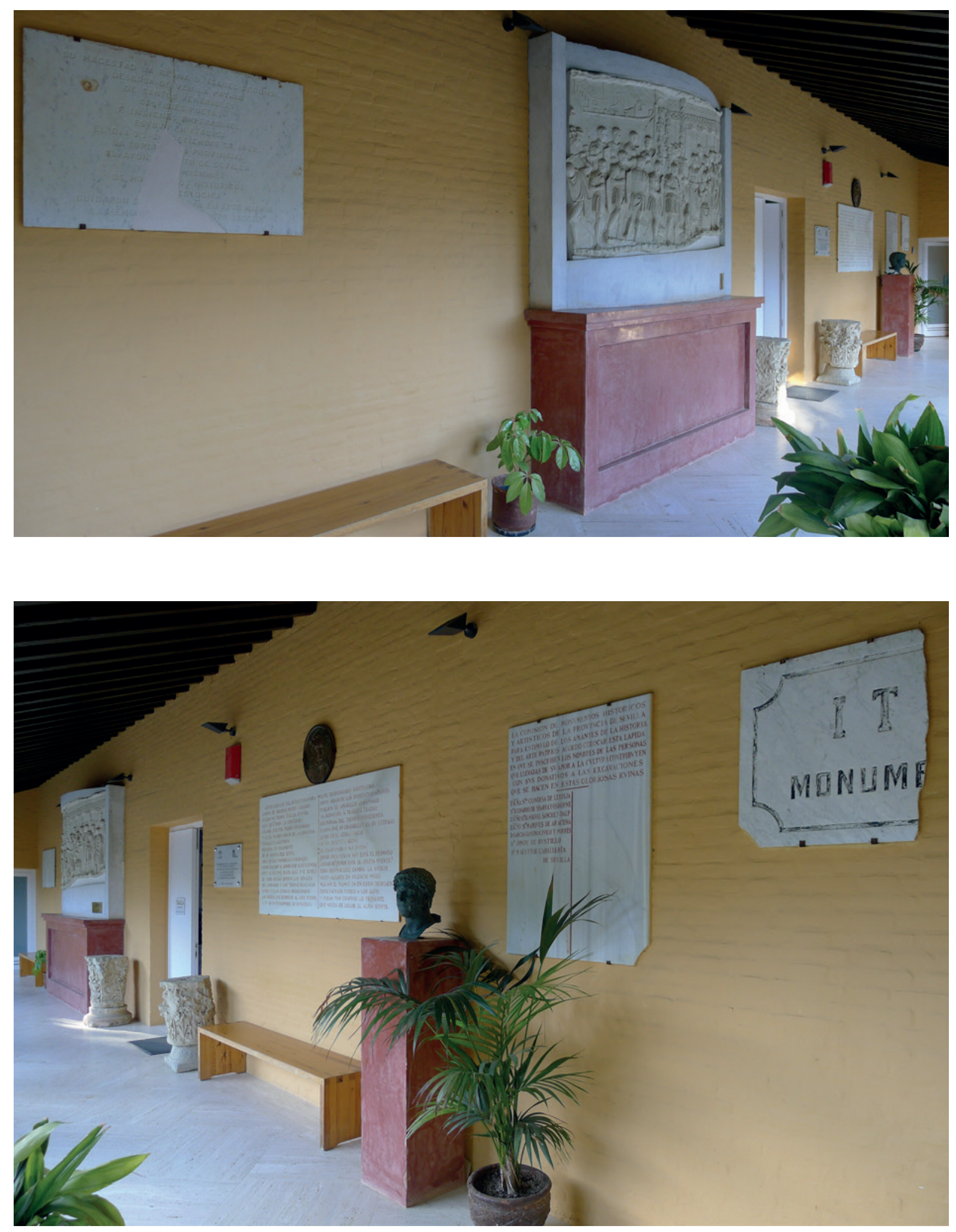

Figs. 10 y 11. Porche de la actual sede institucional donde, en noviembre de 1991, se colocaron las distintas placas conmemorativas rescatadas en 1983 . 


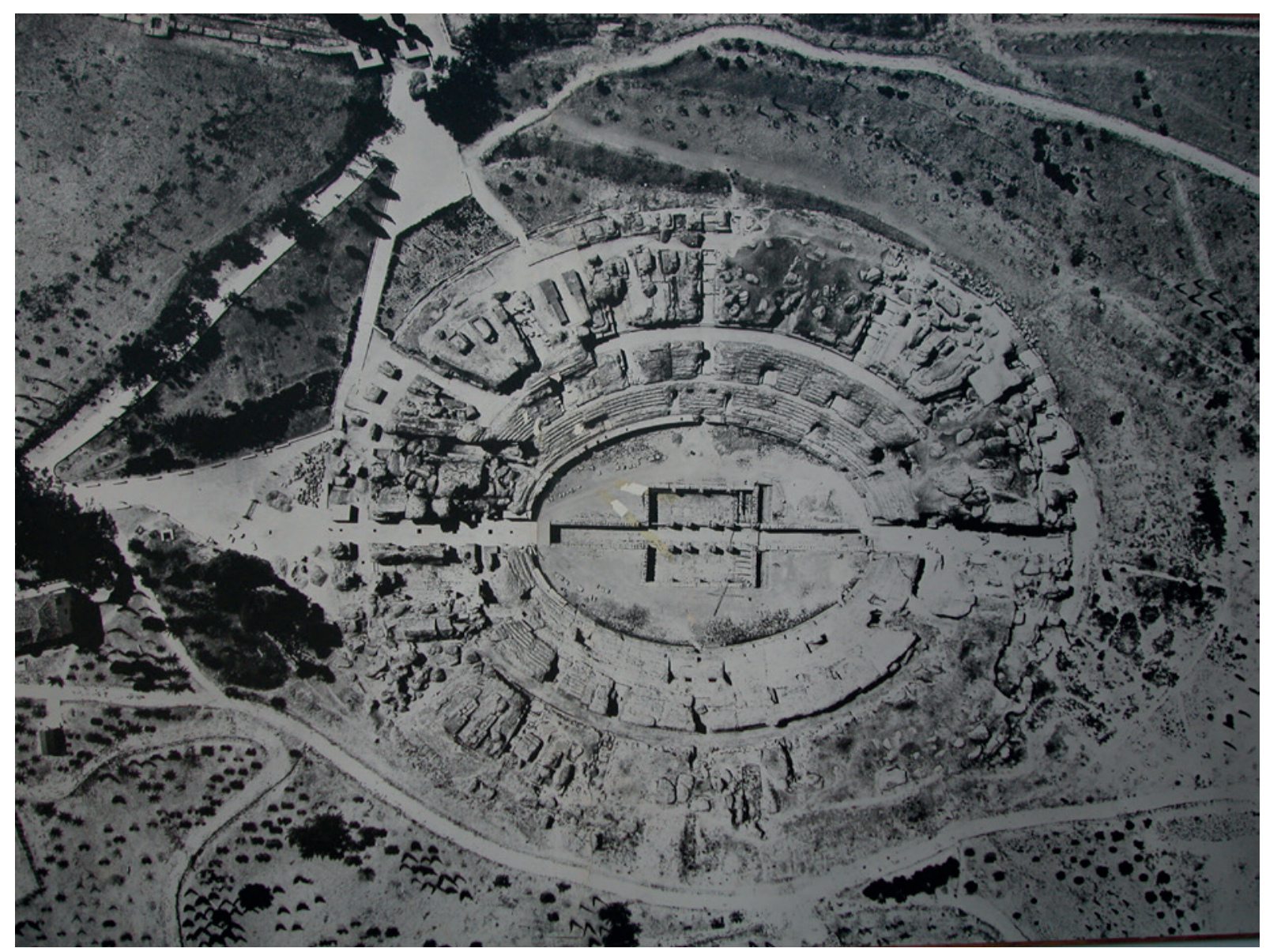

Figura 12. Fotografía aérea del Anfiteatro, 1983. En ella se aprecian los trabajos de restauración en la fachada principal y también los del cuadrante sureste del podium.

cooperación de la misma manera que lo hizo en la primera colocación de la precitada lápida.

Aunque desconocemos la fecha exacta, la lápida fue repuesta, aparentemente en su lugar de origen y allí permaneció, hasta que en la campaña de los años 192425, Andrés Parladé vació y excavó la estancia situada a la derecha de la Avenida Triunfal del Anfiteatro, soterrada hasta entonces y en cuya parte superior, adherida a un gran bloque de opus caementicium, se encontraba la inscripción (Parladé, A., 1926, pp. 3-4). Ésta fue arrancada nuevamente, el bloque roto, la tierra evacuada y la sala excavada, el Nemeseion (Beltrán Fortes, J. y Rodríguez Hidalgo, J. M., 2004, pp. 55-60).

La observación de las fotos de la época nos induce a pensar que, pese al interés manifestado por el Excmo. Ayuntamiento de Sevilla y el asentimiento de la Comisión de Monumentos, la lápida no se recolocó hasta muchos años después (figs. 2 y 3). Creemos que fue en
1906, ahora para la visita de S. M. Alfonso XIII. Alguien debió de acordarse de la lápida que en su día se colocó para conmemorar la visita de la abuela del joven Monarca, también Reina, y se dio la orden de colocar la lápida en el camino que entonces permitía el acceso de bajada a la "plaza del anfiteatro", la arena (fig. 4). En ninguna de las fotos anteriores a la referida fecha de 1906 se evidencia la mencionada lápida, algo que nos induce a manifestar que en 1862 se colocó en un lugar apartado del objetivo de las múltiples cámaras que fotografiaron el Anfiteatro. Tampoco es descartable la posibilidad de que una vez arrancada en 1868 no quedasen restos del mortero de cal con que se fijó la placa de mármol, como suele ser lo habitual (figs.5, 6, 7).

En el año 1983 el arquitecto Alfonso Jiménez Martín ejecutó un proyecto que comportaba la restauración de la fachada del Anfiteatro, allí donde el alzado de la misma tendría su máximo desarrollo en altura. El citado proyecto comportaba la reconstrucción de los

ISSN: 1133-4525 ISSN-e: 2255-3924 


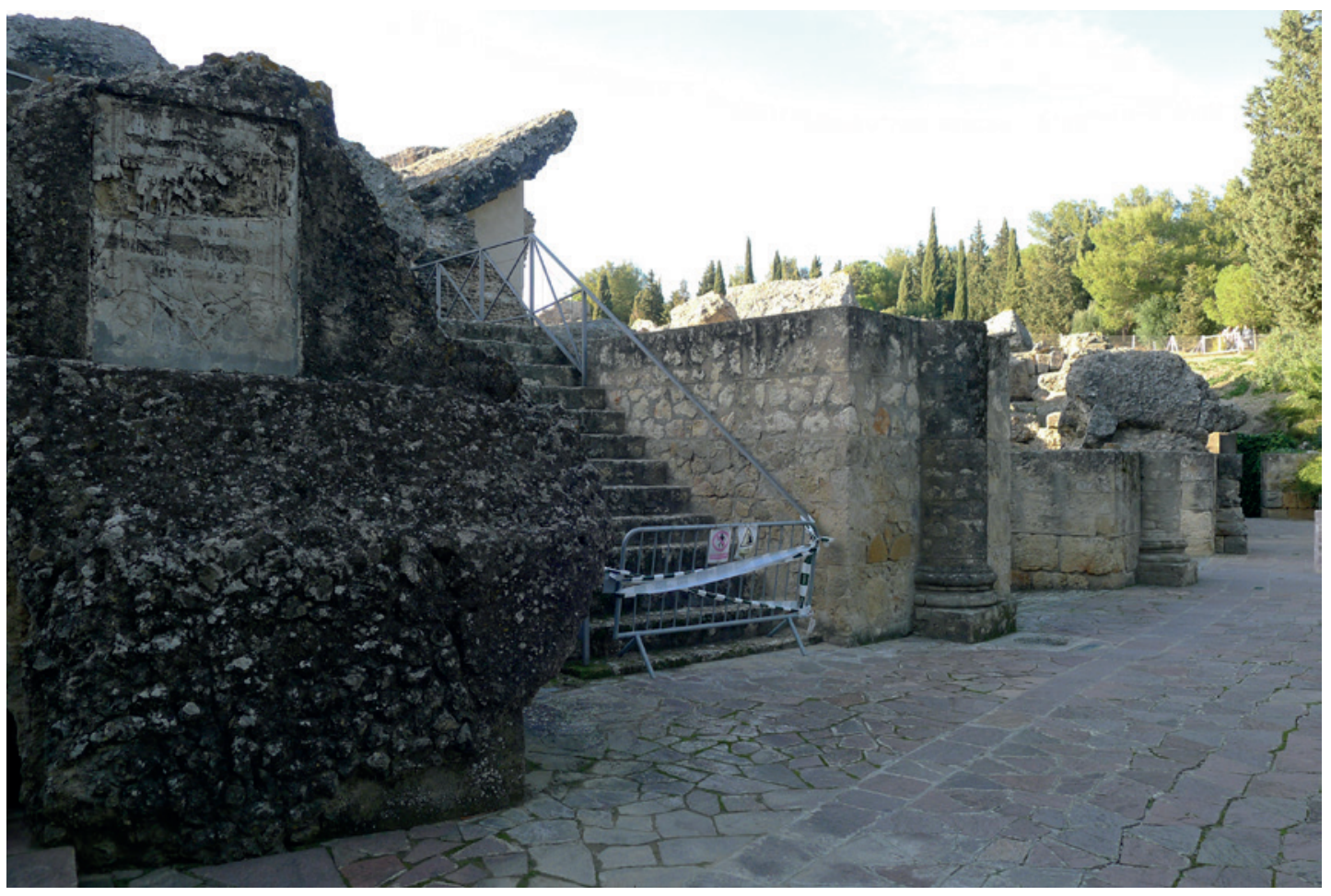

Figura 13. Detalle de la restauración de a fachada principal del Anfiteatro realizada en 1983. En primer término, sobre un bloque de opus caementicium se aprecia la impronta que dejó la placa que colocó la Comisión de Monumentos en reconocimiento a las personas e instituciones que colaboraron en las excavaciones practicadas en Itálica.

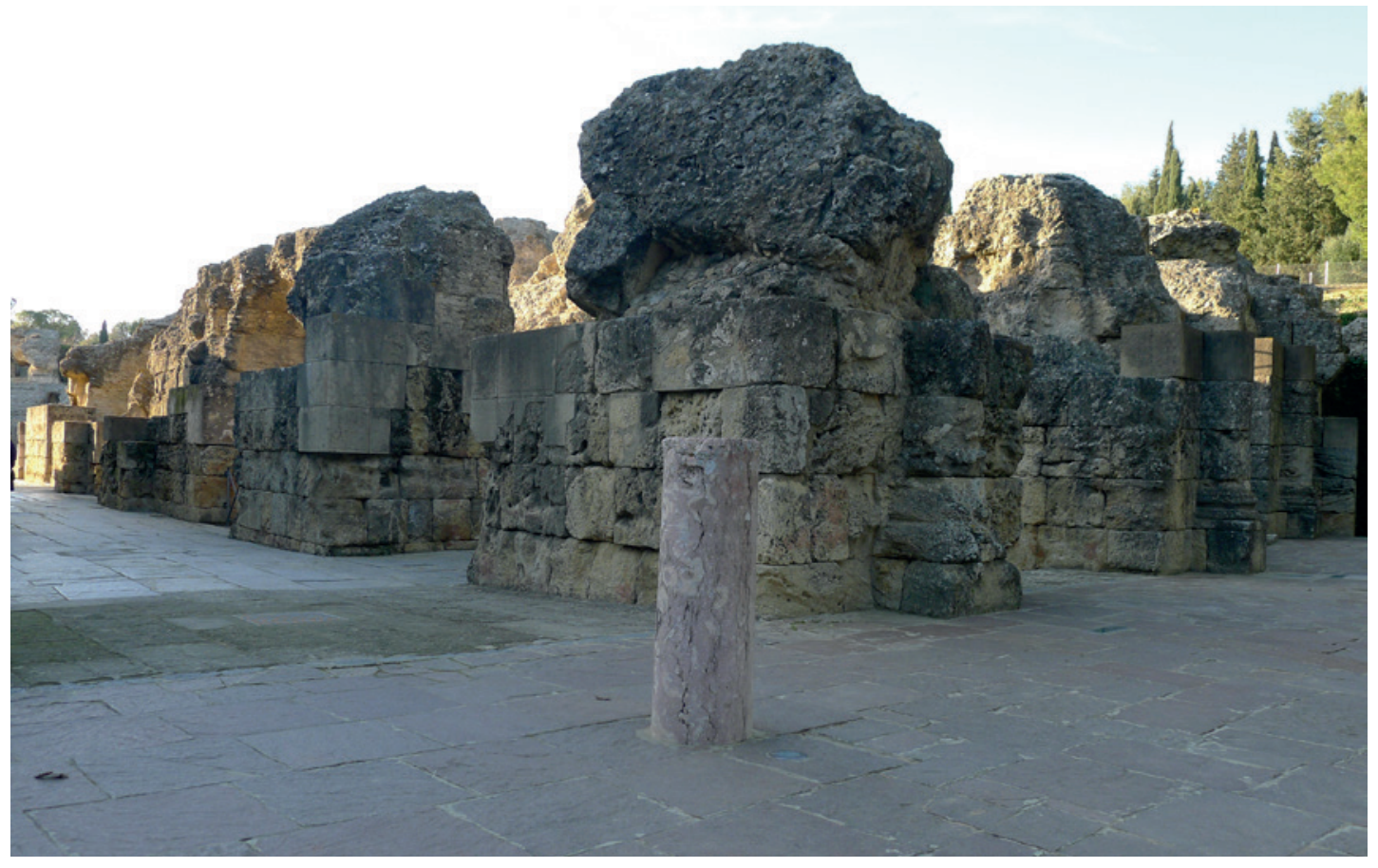

Figura 14. Detalle de la fachada y columna conmemorativa del evento realizado en la arena del Anfiteatro el 20 de mayo de 1862 
dos pilares que, situados a la izquierda de la Puerta Triunfal del edificio, habían sido expoliados hasta los cimientos y también de la escalera izquierda. Esta escalera, que permitía la subida desde la fachada hasta el deambulatorio de la primera planta, se presentaba despojada de su forro de sillares y era prioritario recuperar su función y facilitar así la subida del público visitante.

Previo a las tareas de reconstrucción fue necesario desalojar el entorno inmediato. Allí, a principios de la década de 1970 J. Mª Luzón, en su etapa de director, había depositado todas las cornisas que en su día coronaban el podium del Anfiteatro y que hasta entonces permanecían diseminadas por la arena. Fue necesario catalogarlas y también realizar una excavación, para alcanzar los cimientos de esos pilares que se iban a reconstruir. En ese proceso previo de ordenación de la superficie de trabajo, donde A. Parladé no había concluido la excavación de la fachada, donde por tanto no pudo colocarse el pavimento que Benito Mussolini regaló con motivo de la Exposición Ibero Americana, y donde se había generado un majano de piedras de distinta naturaleza, es donde pudimos recuperar la olvidada "lápida de Isabel II". Pero no sólo recuperamos ese recuerdo de la memoria de Itálica. Allí estaban también otras dos placas de mármol; una, aunque fragmentada, recordaba que Itálica era Monumento Nacional; en la otra la Comisión de Monumentos relacionaba a una serie de personas e instituciones que llevadas por su amor a la cultura habían contribuido a la excavación de Itálica (figs. 8 y 9).

Una vez recuperadas estas tres placas de mármol fueron almacenadas y en otoño de 1991, al poco tiempo de ser nombrado director del Conjunto Arqueológico de Itálica, las coloqué a la vista pública en el porche del edificio administrativo, antes Museo (figs.10, 11 y 12). En esa misma fecha se ubicó en su posición actual, en el eje de la Puerta Triunfal del Anfiteatro, unos dos metros por delante de la línea de fachada, la columna donde en su día se grabaron los versos de Rioja para conmemorar la visita que la Comisión de Monumentos giró a Itálica, el 20 de mayo de 1862, para presenciar las excavaciones realizadas por Demetrio de los Ríos y que concluyó con un recital poético donde se leyeron los versos de aquellos afamados poetas que evocaron con amargas lágrimas la destrucción de Itálica. Ya en 1929, durante la pavimentación de la explanada de entrada al Anfiteatro regalada por Benito Musolini, se colocó aquí, aunque en la línea de fachada; pero fue necesario arrancarla durante las obras de restauración de 1983, ya que en ellas se repuso el tramo de losas existente entre la solería original de la avenida triunfal y la regalada por el Duce. Desde entonces y hasta 1991 permaneció guardada, pero, además de recordar aquel evento pasado, era necesario evitar el acceso a los camiones que, desde el año 1981, entraban en el interior del Anfiteatro, para montar y desmontar el escenario y graderío provisional de los Festivales de Itálica (figs. 13 y 14).

\section{BIBLIOGRAFÍA}

ARCHIVO DE LA COMISIÓN DE MONUMENTOS HISTÓRICOS Y ARTÍSTICOS DE SEVILLA.

COS-GAYÓN, FERNANDO. Crónica del viaje de SS. MM. y AA. RR. a Andalucía y Murcia en septiembre-octubre de 1862. Madrid, 1863.

BELTRÁN FORTES, JOSÉ Y RODRÍGUEZ HIDALGO, JOSÉ MANUEL. Itálica. Espacios de culto en el anfiteatro. Sevilla, 2004

GALI LASSALETTA, AURELIO. Historia de Itálica. Municipio y Colonia Romana. S. Isidoro del Campo. Sepulcro de Guzmán El Bueno. Santiponce, Sevilla. Sevilla, 1892.

MAIER ALLENDE, JORGE Y SALAS ÁlVAREZ, JESÚS. Comisión de Antigüedades de la Real Academia de la Historia. Andalucía. Catálogo e Indices. Madrid, 2000.

PARLADÉ Y HEREDIA, ANDRÉS, CONDE DE AGUIAR. "Excavaciones en Itálica. Memoria de las excavaciones practicadas en 1924-1925". Junta Superior de Excavaciones y Antigüedades, Núm. Gral.: 81. Núm. 11 de 1924-25. Madrid, 1926.

PONGILIONI, ARÍSTIDES E HIDALGO, FRANCISCO DE PAULA. Crónica del Viaje de SS. MM. y AA. RR. a las provincias de Andalucía en 1862. Madrid, 1863.

RÍOS Y SERRANO, DEMETRIO DE LOS. Memoria Arqueológico-Descriptiva del Anfiteatro de Itálica. Madrid 1862.

RODRÍGUEZ HIDALGO, JOSÉ MANUEL. "La colección arqueológica de Itálica. Apuntes sobre su ampliación e institucionalización durante el siglo XIX”, en J. Beltrán et al., eds., Arqueología, Coleccionismo y Antigüedad. España e Italia en el Siglo $X I X$. Sevilla, 2006.

RODRÍGUEZ HIDALGO, JOSÉ MANUEL. "Demetrio de los Ríos e Itálica”, en Ríos, Demetrio, $\mathrm{Me}$ moria Arqueológico-Descriptiva del Anfiteatro de Itálica. Madrid 1862, (reed. Sevilla, 2002). 
TUBINO Y RADA, FRANCISCO MARÍA. La Corte en Sevilla. Crónica del Viaje de SS. MM. Y AA. RR. a las provincias andaluzas. Sevilla, 1863.
VELÁZQUEZ Y SÁNCHEZ, JOSÉ. Crónica Regia, viaje de la Corte a Sevilla en 1862. Sevilla, 1872.

FeCha DE ENTRADA: 02/02/2012

FECHA DE ACEPTACIÓN: 27/02/2012 